\title{
The Effect of Multilayer Gold Nanoparticles on the Electrochemical Response of Ammonium Ion Biosensor Based on Alanine Dehydrogenase Enzyme
}

\author{
Tan Ling Ling, ${ }^{1}$ Musa Ahmad, ${ }^{2}$ Lee Yook Heng, ${ }^{1}$ and Toh Chee Seng ${ }^{3}$ \\ ${ }^{1}$ School of Chemical Sciences and Food Technology, Faculty of Science and Technology, \\ Universiti Kebangsaan Malaysia (UKM) Selangor, 43600 Bangi, Malaysia \\ ${ }^{2}$ Industrial Chemical Technology Program, Faculty of Science and Technology, Universiti Sains Islam Malaysia, Bandar Baru Nilai, \\ Negeri Sembilan, 71800 Nilai, Malaysia \\ ${ }^{3}$ Department of Chemistry, Faculty of Science, National University of Singapore, Singapore 117543
}

Correspondence should be addressed to Lee Yook Heng, leeyookheng@yahoo.co.uk

Received 24 May 2011; Revised 7 August 2011; Accepted 26 August 2011

Academic Editor: Eugenio Martinelli

Copyright ( 2011 Tan Ling Ling et al. This is an open access article distributed under the Creative Commons Attribution License, which permits unrestricted use, distribution, and reproduction in any medium, provided the original work is properly cited.

The use of multilayer of gold nanoparticles (AuNPs) attached on gold electrode surface via thiol chemistry to fabricate an ammonium $\left(\mathrm{NH}_{4}{ }^{+}\right)$ion biosensor based on alanine dehydrogenase $(\mathrm{AlaDH})$ was investigated. The approach of the study was based on construction of biosensor by direct deposition of AuNPs and 1,8-octanedithiol (C8-DT) onto the gold electrode surface. For the immobilisation of enzyme, 2-mercaptoethanol (2BME) was first covalently attached to AlaDH via esther bonding and then followed by chemically attached the 2BME-modified AlaDH (2BME-AlaDH) moiety onto the AuNPs electrode via the exposed thiol group of 2BME. The resulting biosensor response was examined by means of amperometry for the quantification of $\mathrm{NH}_{4}{ }^{+}$ion. In the absence of enzyme attachment, the use of three layers of AuNPs was found to improve the electrochemistry of the gold electrode when compared with no AuNPs was coated. However, when more than three layers of AuNPs were coated, the electrode response deteriorated due to excessive deposition of C8-DT. When AlaDH was incoporated into the AuNPs modified electrode, a linear response to $\mathrm{NH}_{4}{ }^{+}$ion over the concentration range of $0.1-0.5 \mathrm{mM}$ with a detection limit of $0.01 \mathrm{mM}$ was obtained. In the absence of AuNPs, the $\mathrm{NH}_{4}{ }^{+}$ion biosensor did not exhibit any good linear response range although the current response was observed to be higher. This work demonstrated that the incorporation of AuNPs could lead to the detection of higher $\mathrm{NH}_{4}{ }^{+}$ion concentration without the need of dilution for high $\mathrm{NH}_{4}{ }^{+}$ion concentration samples with a rapid response time of $<1$ min.

\section{Introduction}

The rapid development in research on nanoparticles arises from their unique physical and chemical properties. With average particle diameter in the range of nanometer, the particles behave distinctively different from both bulk and atomicscale materials $[1,2]$. Nanomaterials have tremendous potential applications due to their novel and interesting properties. This includes areas such as nanoelectronic, magnetic storage, catalysis, biological assays, sensors, labeling, and cosmetics [2-4]. One of the unique physical characteristics of nanomaterials is the substantial amount of their atomic constituents existed at the particles' surfaces and that the physical properties of nanomaterials are changeable with surface modification of the nanomaterials [1].
Over the past decade, AuNPs have been intensively studied owing to their promising characteristics that are not revealed in bulk gold, namely, small feature particle size, and optical, electronic and chemical properties [3-6]. Numerous investigations entailed the application and preparation of AuNPs have been extensively discussed in the literature, particularly in the fabrication of chemical sensors, biosensors, catalysts, and nonlinear optical devices $[3,6]$. In view of the inferior characteristic of bulk gold electrode with regards to the electrochemically inactive surface, surface-modified gold electrode has been recommended to improve such drawbacks $[3,4]$. Several metal nanoparticles with excellent electrochemical performance such as $\mathrm{Au}, \mathrm{Pt}$, and $\mathrm{Pd}$ have been widely exploited to construct highly active electrodes for 
electrochemical application purposes $[7,8]$. Surface-modified electrode employing AuNPs have gained substantial attention mostly for its interesting electrocatalytic and biosensing capabilities. Immobilisation of AuNPs onto electrode substrate encompassed entrapment, impregnation, deposition-precipitation, electrodeposition, and dip-coating methods $[5,7,8]$.

The binding formed between AuNPs and metal electrode surface can be either electrostatic links [9] or covalent binding [10]. Enzyme immobilisation based on two-dimensional and three-dimensional nanoparticle membranes in the construction of biosensors via electrostatic links have been widely explored due to the large choice of nanomaterials $[11,12]$. Chemical adsorption or covalent binding of AuNPs usually required a bifunctional bridge, which couples the AuNPs to the metal surface, for example, aliphatic diamines and dithiols $[3,11]$. The spontaneous adsorption of thiol $(-\mathrm{SH})$ and amine $\left(-\mathrm{NH}_{2}\right)$ functional groups on the gold surface allows layering of AuNPs to form self-assembled monolayers due to their high affinity towards gold surface [2]. Self-assembly of AuNPs on the metal surface which made use of organic linkers has been examined for various potential applications, for example, optoelectronics, microelectronics and bioscience [2]. This was attributed to the high reactivity of AuNPs' surfaces capable of forming stable covalent bonds with passivative organics molecules [1].

Covalent binding of biological molecules via direct attachment to the electrode surface has been intensively used in the development of biosensors. Association of enzyme molecules with AuNPs was found to have improved biosensor performance due to large immobilisation surface area, high stability, and excellent biocompatibility provided by AuNPs $[12,13]$. It is often a concern on the influences of chemical or physical factors on the immobilised enzyme molecules [10]. To mitigate such problem, modification of electrode surface with AuNPs would guarantee the nature of enzyme molecules retained to its maximum [13]. It has been claimed that the nanometric edges of AuNPs can penetrate a little into the protein molecules to reduce the distance between electrode and enzyme redox sites [10], thereby increased the electron transfer rate $[14,15]$. In contrast, immobilisation of enzyme molecules via physical adsorption method has a shortcoming of lacking stability. As such, covalent biding of enzyme molecules onto AuNPs has been recommended.

In the present study, we demonstrated a simple approach to fabricate a robust AuNPs-based biosensor. A higher immobilisation surface area was acquired by alternate deposition of gold colloid and bifunctional organic linker of C8-DT on the gold electrode surface. The carboxyl (-COOH) functional group of AlaDH enzyme was coupled with hydroxyl $(-\mathrm{OH})$ functional group of $2 \mathrm{BME}$ via esterification reaction under slightly alkaline condition. The $2 \mathrm{BME} / \mathrm{AlaDH}$ enzyme was then immobilised covalently onto AuNPs electrode via Au-S bonds. The design of the multilayer AuNPs-based $\mathrm{NH}_{4}{ }^{+}$ion biosensor is presented in Figure 1. The effect of the increasing layers of AuNPs deposition on the response to $\mathrm{NH}_{4}{ }^{+}$ions was also investigated. In this study, AlaDH enzyme was used as the model enzyme for quantitative determination of $\mathrm{NH}_{4}{ }^{+}$ion concentration in the aqueous surrounding. The investigation of $\mathrm{NH}_{4}{ }^{+}$ion in water is thought to be crucial since it can endanger the aquatic life at concentration and exist in high concentration in domestic waste water [16-18].

\section{Experimental}

2.1. Reagents. All solutions used in this study were prepared using ultrapure water (Nanopure Ultrapure Water System) and all chemicals used were purchased from commercial sources and used without further purification. Gold colloid, $5 \mathrm{~nm}\left(\sim 0.01 \%\right.$ as $\left.\mathrm{HAuCl}_{4}\right)$, was purchased from Sigma-Aldrich in Singapore and used as received. Stock solution of $0.004 \mathrm{mg} / \mu \mathrm{L} \mathrm{L}$-alanine dehydrogenase enzyme (AlaDH, E.C. 1.4.1.1, from Bacillus subtilis) (Sigma) was prepared by dissolving an appropriate amount of AlaDH enzyme in $10 \mathrm{mM}$ phosphate buffer $\mathrm{pH} 7$ in an Eppendorf tube and kept at $4^{\circ} \mathrm{C}$ [19]. $5 \mathrm{mM} \beta$-nicotinamide adenine dinucleotide, reduced form (NADH, 98\%) was obtained from Sigma and prepared with ice-cold $10 \mathrm{mM}$ phosphate buffer $\mathrm{pH} 7$ and used promptly. $1 \mathrm{mM} 2 \mathrm{BME}\left(\mathrm{C}_{2} \mathrm{H}_{6} \mathrm{OS}, 99 \%\right.$, Sigma-Aldrich) was prepared by mixing an adequate amount of $2 \mathrm{BME}$ with ultrapure water. Stock solution of $5 \mathrm{mM}$ sodium pyruvate $\left(\mathrm{C}_{3} \mathrm{H}_{3} \mathrm{NaO}_{3}, 99 \%\right.$, Sigma $)$ was prepared by dissolving an appropriate amount of pyruvate salt in ultrapure water. $10 \mathrm{mM}$ phosphate buffer $\mathrm{pH} 7$ was prepared by adding $10 \mathrm{mM}$ dipotassium hydrogen phosphate $\left(\mathrm{K}_{2} \mathrm{HPO}_{4}, 98 \%\right.$, Sigma) to $10 \mathrm{mM}$ potassium dihydrogen phosphate $\left(\mathrm{KH}_{2} \mathrm{PO}_{4}, 99.5 \%\right.$, Sigma) and adjusted to the desired $\mathrm{pH}$ value [19]. Standard ammonia stock solution was prepared by dissolving concentrated ammonia solution $\left(\mathrm{NH}_{3}, 25 \%\right.$, MERCK) with ultrapure water. The ammonia solution used has been standardised with Nessler method using ammonium chloride $\left(\mathrm{NH}_{4} \mathrm{Cl}, 99.5 \%\right.$, MERCK) salt. 1,8-octanedithiol $\left(\mathrm{C}_{8} \mathrm{H}_{18} \mathrm{~S}_{2}\right.$, 97\%) from Aldrich was dissolved in an absolute ethanol $\left(\mathrm{C}_{2} \mathrm{H}_{5} \mathrm{OH}\right.$, Riedel de Haen, $\left.99.9 \%\right)$ and made up to a final concentration of $0.3 \mathrm{mM}$.

2.2. Instrumentation. Cyclic voltammetry (CV) and chronoamperometry experiments were conducted using CHI 440 Electrochemical Workstation (CH Instrument, USA) in a three-electrode electrochemical cell. The working electrode used was gold electrode (Model CHI101, 2 mm diameter). Platinum gauze and $\mathrm{Ag} / \mathrm{AgCl}$ saturated with $\mathrm{KCl}$ served as auxiliary and reference electrodes, respectively. The surface morphology images of AuNPs electrodes were acquired using a field emission scanning electron microscopic instrument (XL30-FEG SEM, FEI Company with $5 \mathrm{kV}$ operating voltage) equipped with an energy dispersive X-ray analyzer (EDX). Measurements of $\mathrm{pH}$ were made with Metrohm $744 \mathrm{pH}$ meter.

\subsection{Electrode Pretreatment and Surface Characterisation.} Electrode pretreatment was carried out with a method as reported by Tkac and Davis [20] with some modifications. The gold electrode was pretreated via reductive desorption in $0.1 \mathrm{M} \mathrm{NaOH}$ with 100 repetitive $\mathrm{CV}$ scans between $-0.5 \mathrm{~V}$ and $-1.5 \mathrm{~V}$ versus $\mathrm{Ag} / \mathrm{AgCl}$ at a scan rate of $1 \mathrm{Vs}^{-1}$. This procedure was necessary for the thorough removal of any 


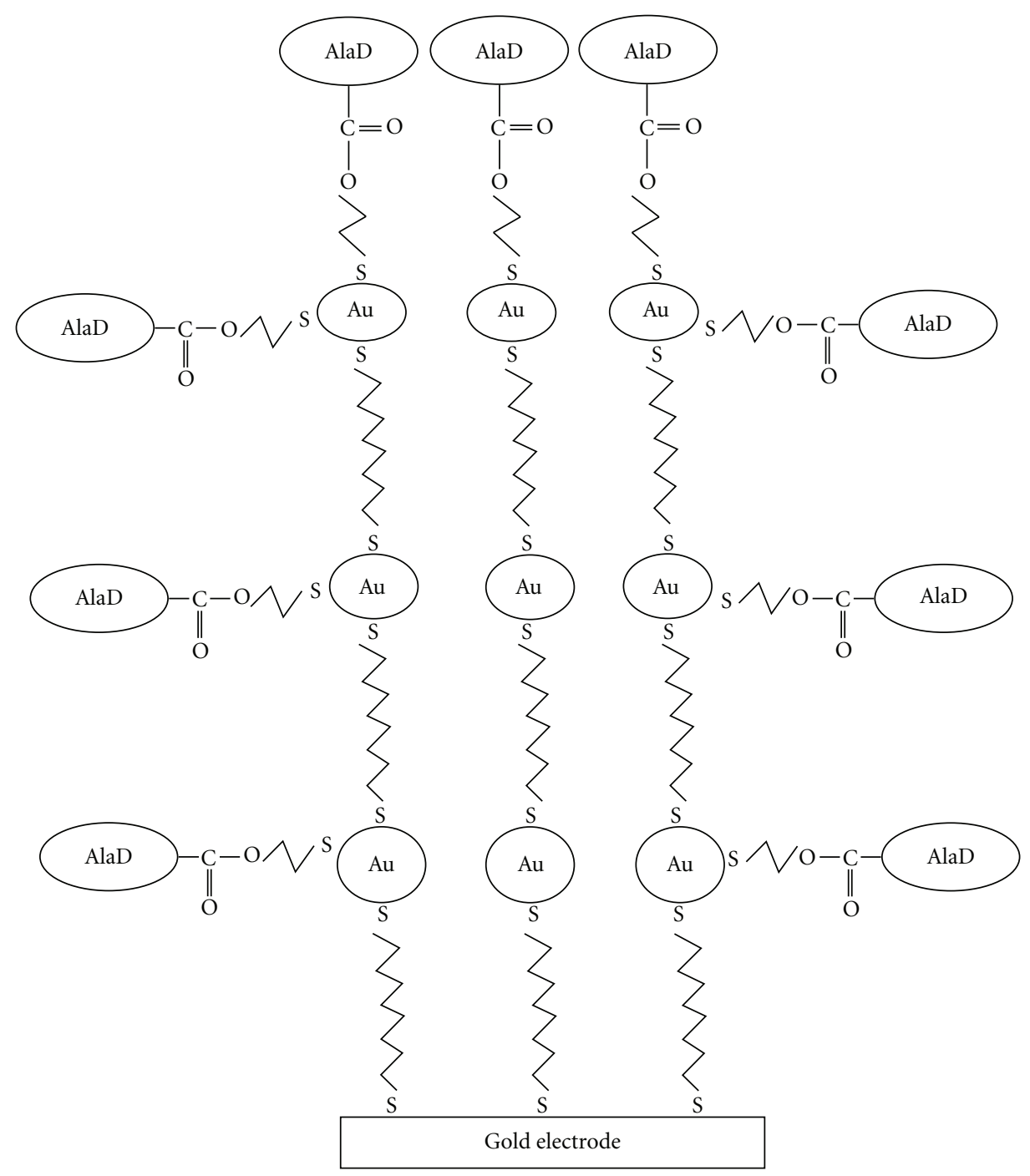

FIgURE 1: The design of $\mathrm{NH}_{4}{ }^{+}$ion biosensor based on immobilised 2BME/AlaDH enzyme on the AuNPs electrode.

adsorbate traces from previous experiments. The gold electrode was then mechanically polished with $0.3 \mu \mathrm{m}$ alumina slurry on a polishing cloth (Allied) for $4 \mathrm{~min}$, rinsed and cleaned ultrasonically for $2 \mathrm{~min}$ in ultrapure water to remove residual alumina particles. The chemical pre-treatment of gold electrode was done by immersing the gold electrode into hot piranha solution $\left(\mathrm{H}_{2} \mathrm{SO}_{4}: \mathrm{H}_{2} \mathrm{O}_{2}, 3: 1\right)$ for $15 \mathrm{~min}$, followed by rinsing and ultrasonic cleaning with ultrapure water for $2 \mathrm{~min}$. The electrode was then transferred to an electrochemical cell and electrochemical polishing was performed with 25 successive $\mathrm{CV}$ scans between $-0.2 \mathrm{~V}$ and $+1.5 \mathrm{~V}$ versus an $\mathrm{Ag} / \mathrm{AgCl}$ reference in $0.1 \mathrm{M} \mathrm{H}_{2} \mathrm{SO}_{4}$ at scan rate of $0.1 \mathrm{Vs}^{-1}$. Electrochemical gold oxide stripping was performed with 10 repetitive $\mathrm{CV}$ scans from $+0.75 \mathrm{~V}$ to $+0.2 \mathrm{~V}$ versus $\mathrm{Ag} / \mathrm{AgCl}$ in $0.1 \mathrm{M} \mathrm{H}_{2} \mathrm{SO}_{4}$ at scan rate of $0.1 \mathrm{Vs}^{-1}$. Finally, the chemical reduction of gold oxide was performed by soaking the electrode in absolute ethanol under nonstirred conditions for $20 \mathrm{~min}$ at room temperature $\left(24.4^{\circ} \mathrm{C}\right)$ and thereafter dried under argon gas.
The AuNPs deposition on the gold electrode was examined via SEM. Samples of various layers were prepared using gold quartz substrates (CHI125, polished, bound, mounded $100 \mathrm{~A} \mathrm{Ti}+1000 \mathrm{~A}$ Gold crystal) that was cleaned with piranha solution. $0.5 \mu \mathrm{L}$ of gold colloid and $1 \mu \mathrm{L}$ of $0.3 \mathrm{mM}$ C8-DT were alternately drop-coated onto different gold quartz substrates and left overnight. The samples were then rinsed repeatedly with absolute ethanol and dried with Ar gas before being examined using SEM instrument.

2.4. Construction of Multilayer AuNPs-Based $\mathrm{NH}_{4}{ }^{+}$Ion Biosensor. Multilayer AuNPs-based biosensor was fabricated by depositing $0.5 \mu \mathrm{L}$ of colloidal AuNPs onto gold electrode surface and dried at room temperature for $15 \mathrm{~min} .1 \mu \mathrm{L}$ of $0.3 \mathrm{mM}$ C8-DT was then deposited onto the AuNPs electrode and kept at ambient temperature for $30 \mathrm{~min}$. Multilayer of AuNPs was formed by repeating the above deposition method for AuNPs and C8-DT on the gold electrode. The AuNPs electrode was stored overnight $(24 \mathrm{hrs})$ at room temperature 
after deposition of the last C8-DT layer. Then, the modified electrode was immersed in absolute ethanol for $15 \mathrm{~min}$, rinsed repeatedly with abundant absolute ethanol to remove the unreacted nanoparticles and free dithiols followed by purging with Ar gas for a few minutes. $50 \mu \mathrm{L}$ of $0.008 \mathrm{mg} / \mu \mathrm{L}$ $\mathrm{AlaDH}$ enzyme was then reacted with $50 \mu \mathrm{L}$ of $1 \mathrm{mM} 2 \mathrm{BME}$ under slightly alkaline condition for an hour. Finally $2 \mu \mathrm{L}$ of 2BME/AlaDH enzyme solution was then drop-coated onto the AuNPs electrode and stored overnight at $4^{\circ} \mathrm{C}$. The 2BME/AlaDH enzyme-modified AuNPs electrode was finally soaked in buffer solution for $15 \mathrm{~min}$ and rinsed repeatedly with abundant buffer solution to remove any unbound 2BME/AlaDH enzyme.

2.5. Optimisation of Biosensor Response. Optimisation of AuNPs electrode response was performed via cathodic reduction of gold oxide in $5 \mathrm{~mL}$ of $0.1 \mathrm{M} \mathrm{H}_{2} \mathrm{SO}_{4}$ solution using CV method from $-0.2 \mathrm{~V}$ to $+1.5 \mathrm{~V}$ versus $\mathrm{Ag} / \mathrm{AgCl}$ reference electrode. Bare gold electrode, C8-DT-modified gold electrode, and AuNPs-modified gold electrodes were investigated by running eight consecutive $\mathrm{CV}$ scans at scan rate between $50 \mathrm{mV} / \mathrm{s}$ and $200 \mathrm{mV} / \mathrm{s}$.

The response of AuNPs-based biosensor towards $\mathrm{NH}_{4}{ }^{+}$ ion was examined with the $\mathrm{CV}$ method in the presence and absence of $1.6 \mathrm{mM} \mathrm{NH}_{4}{ }^{+}$ion in $4 \mathrm{~mL}$ of $10 \mathrm{mM}$ phosphate buffer ( $\mathrm{pH} 7$ ). The potential was cycled between $-1.00 \mathrm{~V}$ to $1.00 \mathrm{~V}$ versus $\mathrm{Ag} / \mathrm{AgCl}$ reference electrode at a scan rate of $100 \mathrm{mV} / \mathrm{s}$. The experiment was conducted under non-stirred condition in the presence of $0.1 \mathrm{mM}$ pyruvate and $0.2 \mathrm{mM}$ $\mathrm{NADH}$.

The enzyme-modified AuNPs electrode was then used for quantitative determination of $\mathrm{NH}_{4}{ }^{+}$ion with chronoamperometric method at a fixed potential of $+0.55 \mathrm{~V}$ in a stirred electrolyte solution containing $4 \mathrm{~mL}$ of $10 \mathrm{mM}$ phosphate buffer $\mathrm{pH}$ 7. The experiment was conducted in the presence of $0.1 \mathrm{mM}$ pyruvate and $0.2 \mathrm{mM} \mathrm{NADH}$ with $\mathrm{NH}_{4}{ }^{+}$ion concentrations varied from $0.1 \mathrm{mM}$ to $1.4 \mathrm{mM}$.

\section{Results and Discussion}

3.1. Optimisation of AuNPs Electrode Response. During potential scanning between $-0.2 \mathrm{~V}$ and $+1.5 \mathrm{~V}$ versus $\mathrm{Ag} / \mathrm{AgCl}$ reference electrode with bare gold electrode, C8-DT-modified gold electrode, and AuNPs-modified gold electrodes in $0.1 \mathrm{M} \mathrm{H}_{2} \mathrm{SO}_{4}$ solution, single cathodic peak was observed at approximately $+0.9 \mathrm{~V}$ where the peak position was found in agreement with previously reported voltammetric gold oxide reduction [20].

Cyclic voltammograms of bare gold electrode, C8-DTmodified gold electrode, and AuNPs electrodes showed that the cathodic peak current $\left(i_{\mathrm{pc}}\right)$ response was proportional to the square root of scan rate $\left(v^{1 / 2}\right)$ from $50 \mathrm{mV} / \mathrm{s}$ to $200 \mathrm{mV} / \mathrm{s}$. The linear behavior of $i_{\mathrm{pc}}$ versus $v^{1 / 2}$ suggested that the number of redox sites at the electrode surface was constant in the sweep rate interval studied. This is expected for a diffusioncontrolled electron transfer process $[12,21]$. However, the nonzero intercept of $i_{\mathrm{pc}}$ versus $v^{1 / 2}$ plost may be attributed to the nonfaradaic current from the solution electronic resistance [21].
As observed, no significant increment in $i_{\mathrm{pc}}$ signals over the scan rates for 1-layer AuNPs deposited on the electrode compared to the bare gold electrode without any deposition of AuNPs. Further addition of AuNPs layer consistently resulted in a significant increase in $i_{\mathrm{pc}}$ signals, for example, for 2-layer and 3-layer AuNPs depositions. The use of more AuNPs layers appears to improve the $i_{\mathrm{pc}}$ signal when compared with the bare gold electrode. This is attributed to the high reactivity of AuNPs on the electrode surface, which favors the electron transfer kinetics. Also further increase in the number of AuNPs layers has generated more conductive pathways for electron transfer through the immobilised AuNPs, and this has increased the $i_{\mathrm{pc}}$ signal. The lower current responses observed for bare gold electrode and 1-layer AuNPs electrode indicated that the surfaces of these electrodes have less electron transfer.

Although AuNPs can provide conduction pathways to accelerate electron transfer because of their excellent conductivity characteristic [12], layers of AuNPs exceeded 3-layer have resulted in a decline in $i_{\mathrm{pc}}$ signal. This may be explained by the electron transported through AuNPs that is now interrupted by the increasing number of insulating thiol layers [11]. This has further hindered the reduction of gold oxide at the electrode surface as the organic linker layers increase. The C8-DT-modified gold electrode also exhibited low $i_{\mathrm{pc}}$ response over the scan rates studied. The reduction of gold oxide was impeded by the slow electron transfer kinetics through the passivating dithiol layers, which functioned as a barrier of interfacial electron transfer [12]. As the electrode with 3-layer AuNPs gave the highest response towards voltammetric gold oxide reduction, therefore, it was employed for enzyme immobilisation in the construction of an amperometric $\mathrm{NH}_{4}{ }^{+}$ion biosensor in subsequent work.

3.2. Results from Scanning Electron Microscopy. The 2-dimensional arrays of gold colloids had been previously shown to assemble on surface coated with organic linkers [22]. It is assumed that the bifunctional linker C8-DT has one thiol group bound to the gold electrode surface and left the other thiol group free to bind with AuNPs. The SEM studies indicated that the increasing coverage of the AuNPs was associated with the increasing number of AuNPs layer assembled on the gold substrate. Figures 2(a) and 2(b) show the surface morphology of 1 layer and 5 layers of AuNPs immobilised on the gold substrates.

Higher coverage of AuNPs was observed for 5 layers of AuNPs compared with 1 layer AuNPs. Agglomerated gold clusters were also observed apart from AuNPs (Figure 2(b)) when five layers of coating were performed. It can be clearly seen from the SEM image that the AuNP aggregates have estimated diameter of $18.4 \pm 3.5 \mathrm{~nm}$. The formation of AuNP aggregates led to a smaller electrode surface area when compared with that supposed to be created by nonaggregated AuNPs. This is the reason why an increase in too many layers of AuNPs did not show any clear increase in the observed reduction current for gold oxide when AuNPs coated on gold electrode was more than three layers.

3.3. $\mathrm{NH}_{4}{ }^{+}$Ion Biosensor Response. Figure 3 illustrates the cyclic voltammograms of a biosensor for $\mathrm{NH}_{4}{ }^{+}$ion based on 


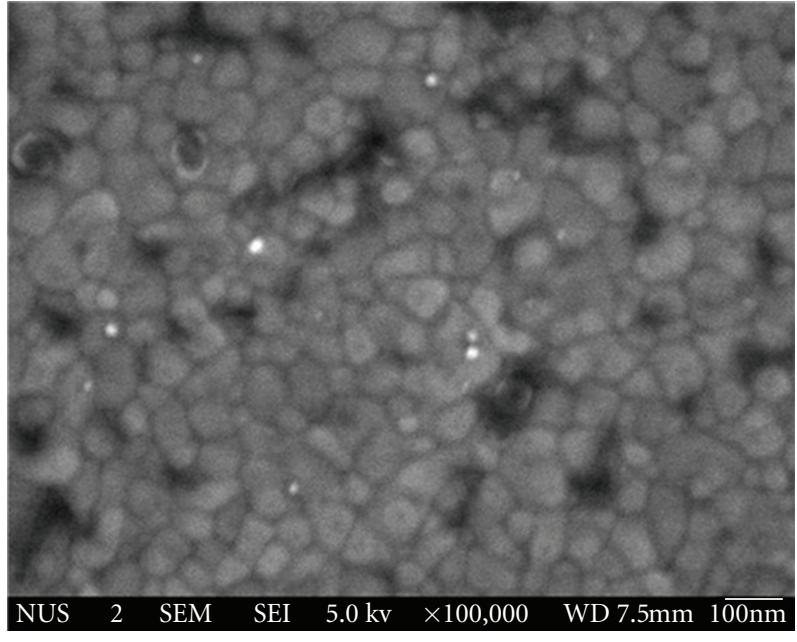

(a)

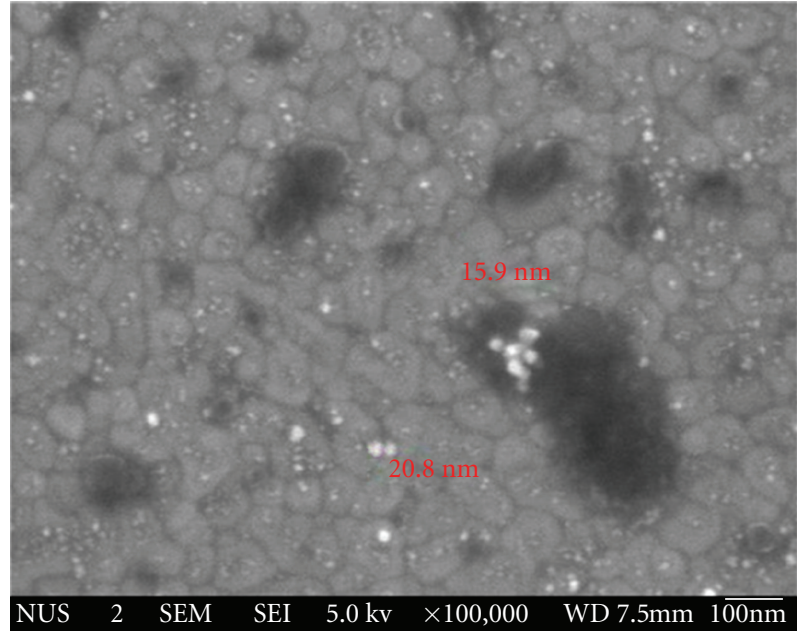

(b)

FIGURE 2: Scanning electron micrographs of gold substrates coated with (a) one layer and (b) five layers of AuNPs using colloidal Au particles of $5 \mathrm{~nm}$. AuNPs mainly appeared as discrete bright dots.

a gold electrode modified with immobilised 2BME/AlaDH enzyme with a 3-layer AuNPs. The oxidation current of the biosensor increased after an addition of $\mathrm{NH}_{4}{ }^{+}$ion in the positive potential region of $0.3-1.0 \mathrm{~V}$. This was due to the electrocatalytic oxidation of NADH during enzymatic conversion of pyruvate to L-alanine in the presence of $\mathrm{NH}_{4}{ }^{+}$ion as indicated by (1) [23-26]:

$$
\begin{gathered}
\text { Pyruvate }+\mathrm{NADH}+\mathrm{NH}_{4}^{+} \longrightarrow \mathrm{L} \text {-alanine }+\mathrm{NAD}^{+}+\mathrm{H} 2 \mathrm{O} \\
\mathrm{NADH} \longrightarrow \mathrm{NAD}^{+}+\mathrm{H}^{+}+2 \mathrm{e}^{-}
\end{gathered}
$$

Chovin et al. [27] reported that the oxidation of NADH was irreversible on a gold electrode at $+0.8 \mathrm{~V}$ versus $\mathrm{Ag} / \mathrm{AgCl}$ reference electrode due to the rapid protonation that occurred in $\mathrm{NAD}^{+} / \mathrm{NAD}$ redox couple.

In the present work, a fixed potential of $+0.55 \mathrm{~V}$ versus $\mathrm{Ag} / \mathrm{AgCl}$ reference electrode was chosen as the working potential for the determination of $\mathrm{NH}_{4}{ }^{+}$ion response in subsequent chronoamperometric measurements. This is because a lower potential is always preferred to avoid side reactions that may interfere with the biosensor response [28]. The applied potential of $+0.55 \mathrm{~V}$ versus $\mathrm{Ag} / \mathrm{AgCl}$ reference was employed by Raj and Behera [29] using 4,6-diamino-2-mercaptopyrimidine-modified gold electrode and by Behera and Raj [30] by using thiocytosine-modified gold electrode for $\mathrm{NADH}$ oxidation.

During the constant potential measurements, steadystate amperometric responses obtained for the biosensor showed a rapid response (within seconds) after each addition of $\mathrm{NH}_{4}{ }^{+}$ion, which is an indication of the good electrocatalytic behavior of the AuNPs-based $\mathrm{NH}_{4}{ }^{+}$ion biosensor (Figure 4).

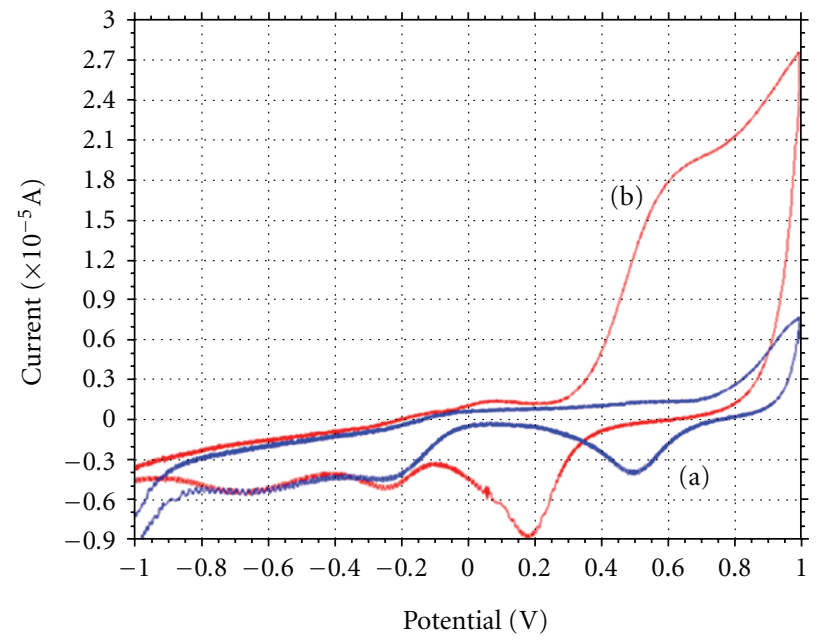

FIGURE 3: Cyclic voltammograms of a gold electrode modified with immobilised 2BME/AlaDH enzyme and coated with 3-layer AuNPs in the absence (a) and presence (b) of $1.6 \mathrm{mM} \mathrm{NH}_{4}{ }^{+}$ion. The measurement was conducted in the presence of $0.1 \mathrm{mM}$ pyruvate and $0.2 \mathrm{mM} \mathrm{NADH}$ at $\mathrm{pH} 7$ with a scan rate of $100 \mathrm{mV} / \mathrm{s}$.

The $\mathrm{NH}_{4}{ }^{+}$ion biosensor modified with AuNPs gave response that followed the Michaelis-Menten kinetic characteristics with a linear response at low $\mathrm{NH}_{4}{ }^{+}$ion concentrations and saturation response at high concentrations (Figure 5). However, the current response of AuNPs-based biosensor was found to be lower when compared with the biosensor based on a gold electrode without modification with AuNPs (Figure 5). This is in agreement with experiment performed earlier using reduction of gold electrode as an indicator for electron transfer where coating of more than three layers of AuNPs led to poorer electrochemistry on gold electrode. The lower response to $\mathrm{NH}_{4}{ }^{+}$ion of electrode modified with AuNPs when compared without AuNPs may be explained 


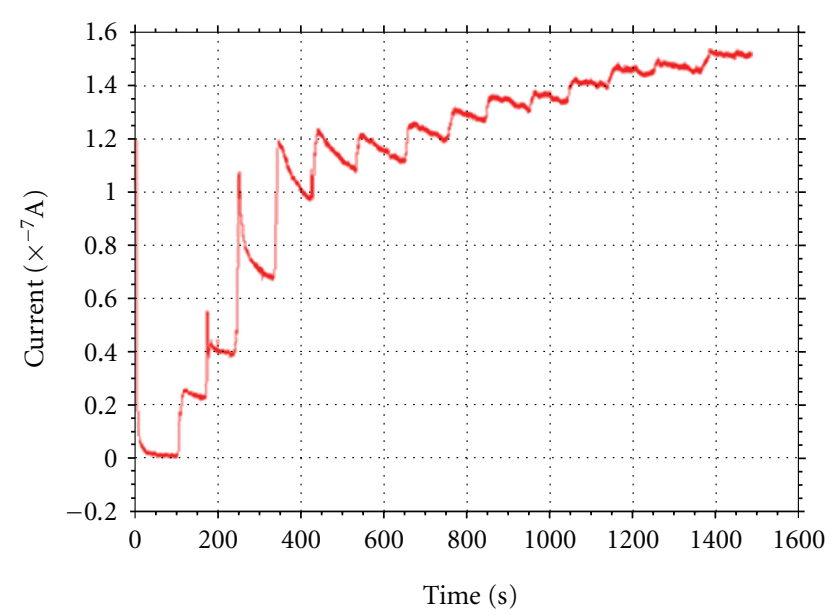

Figure 4: Steady-state amperometric response towards successive additions of $\mathrm{NH}_{4}{ }^{+}$ion at $0.55 \mathrm{~V}$ in $10 \mathrm{mM}$ phosphate buffer $\mathrm{pH} 7$ using gold electrode modified with immobilised enzyme and 3-layer AuNPs.

by the lower immobilisation loads of the $2 \mathrm{BME} / \mathrm{AlaDH}$ enzymes as the AuNPs' surfaces might have been almost fully attached with the C8-DT linkers, which have longer carbon chain and thus a larger electrode passivative character that leads to poorer electron transfer during enzymatic reactions. Based on Figure 6, the biosensor modified with AuNPs demonstrated a linear response range to $\mathrm{NH}_{4}{ }^{+}$ion from $0.1-$ $0.5 \mathrm{mM}$ with an estimated detection limit of $0.01 \mathrm{mM}$. For the biosensor without modification with AuNPs, no good linear response range can be obtained at the low $\mathrm{NH}_{4}^{+}$ion concentration region (from $0.1-0.5 \mathrm{mM}, y=7.206 x+0.234$, $\left.R^{2}=0.958\right)$.

The Michaelis-Menten constant $\left(K_{m}\right)$ can be estimated by a direct linear method based on Lineweaver-Burk plot using the acquired experimental data [31]. In this study, the estimated $K_{m}$ value for 2BME/AlaDH-modified gold electrode was $0.945 \mathrm{mM}$ from the Lineweaver-Burk plot, whist the $K_{m}$ value for 2BME/AlaDH-modified AuNPs electrode was $0.526 \mathrm{mM}$ (Figure 7). A decrease in the $K_{m}$ value when AuNPs were used in modifying the biosensor design indicated that the immobilised enzyme now possessed a higher enzyme activity. The $K_{m}$ value of immobilised 2BME/AlaDH enzyme was also found to be lower than that of the free enzyme in solution (17.3 mM) [32] as the diffusion process has been restricted upon immobilisation, and that the affinity of the immobilised enzyme against $\mathrm{NH}_{4}{ }^{+}$ion has much improved. However, there is no clear relation between the $K_{m}$ values with the sensitivity of the biosensor $[33,34]$. The small $K_{m}$ value obtained for AuNPs-modified transducer suggested a stronger enzyme binding upon enzyme immobilisation on the AuNPs matrix. Thus, the enzyme integrity was maintained to a greater degree upon immobilisation [35].

A comparison of the the AuNPs-based $\mathrm{NH}_{4}{ }^{+}$ion biosensor performance with published work is summarised in Table 1. It is noticed that the $\mathrm{NH}_{4}{ }^{+}$ion biosensors demonstrated a linear response range that is in higher concentrations when compared with reported work that used a

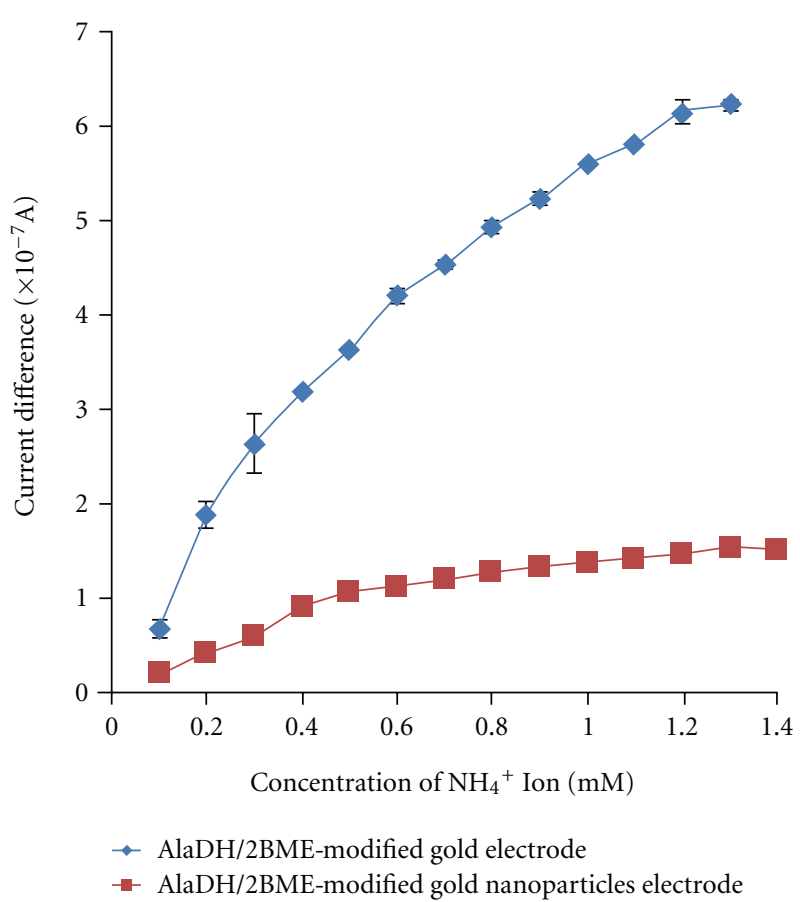

FIGURE 5: The response curves of biosensors with/without coated AuNPs towards different $\mathrm{NH}_{4}{ }^{+}$ion concentrations in the range of $0.1-1.4 \mathrm{mM}$ at $\mathrm{pH}$ 7. Each point is $n=3, \mathrm{RSD}=0.3-15.3 \%$.

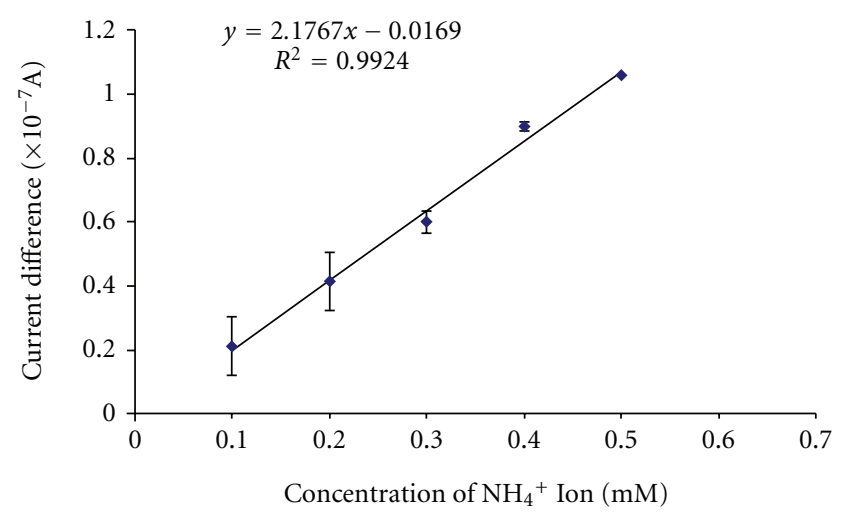

Figure 6: The linear response range produced by 2BME/AlaDHmodified AuNPs electrode in the $\mathrm{NH}_{4}{ }^{+}$ion concentration range of $0.1-0.5 \mathrm{mM}$ at $\mathrm{pH}$ 7. Each point is $n=3$.

poly(carbamoyl) sulfonate (PCS) hydrogel to immobilise bienzyme GLDH/glutamate oxidase or nylon net with GLDH enzyme. The higher concentration for the linear response range of the biosensor modified with AuNPs suggested that the immobilised enzyme affinity towards $\mathrm{NH}_{4}{ }^{+}$ion has been increased where the enzyme saturation is now at higher $\mathrm{NH}_{4}{ }^{+}$concentrations. A similar behaviour was also observed by Sharina et al. [34] when AuNPs was immobilised on a membrane-based amperometric phenol biosensor where the AuNPs were assumed to adsorb enzyme molecules without the loosing of the enzyme activity. Because of the use of AuNPs, the biosensor reported here also demonstrated much faster response time $(<1 \mathrm{~min})$ when compared with reported 
TABLE 1: The comparison between AuNPs-based $\mathrm{NH}_{4}{ }^{+}$ion biosensor and reported amperometric $\mathrm{NH}_{4}{ }^{+}$ion biosensors.

\begin{tabular}{lccc}
\hline Parameters & Present study & Bertocchi et al. [36] & Kwan et al. [37] \\
\hline Enzyme & AlaDH & GLDH & GLDH and glutamate oxidase \\
Immobilisation matrix & AuNPs & Nylon net & PCS hydrogel \\
Linear response range $(\mathrm{mM})$ & $0.5-1.3$ & $0.01-0.2$ & $0.01-0.30$ \\
Detection limit $(\mathrm{mM})$ & 0.01 & 0.01 & 0.002 \\
Response time $(\mathrm{min})$ & $<1$ & - & 20 \\
\hline
\end{tabular}

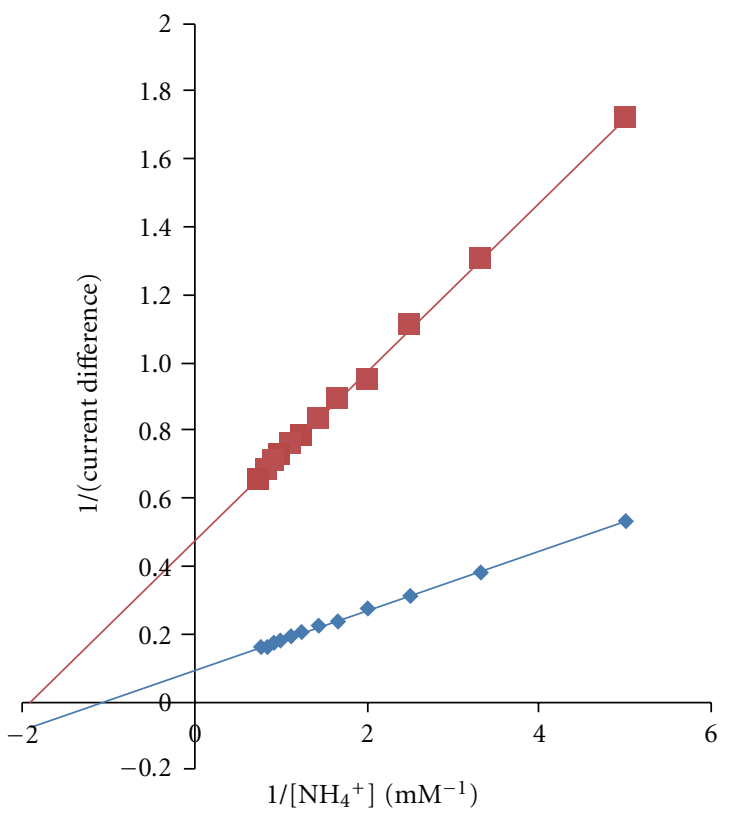

$\rightarrow$ AlaDH/2BME-modified gold electrode

$\rightarrow$ AlaDH/2BME-modified gold nanoparticles electrode

FIGURE 7: Lineweaver-Burk plots of biosensor based on immobilised 2BME/AlaDH enzyme on the gold electrode and biosensor modified with 3-layer AuNPs.

membrane-based amperometric biosensors for $\mathrm{NH}_{4}{ }^{+}$ion. The improvement in the response time is probably attributed to the overall better diffusion when AuNPs were used when compared with polymer-based immobilisation matrices. The rapid response was also due to the better electron transfer through conductive multilayer AuNPs when compared with polymer membranes.

\section{Conclusions}

The effect of deposition of multilayer AuNPs via C8-dithiols on gold surface electrochemistry has been demonstrated. The presence of AuNPs could improve the electron transfer but too much of C8-dithiols deposited led to a decrease in the gold electrode response because of the insulating behavior of the C8-dithiols. However, the AuNPs played an important role in improving the immobilised AlaDH enzyme affinity towards $\mathrm{NH}_{4}{ }^{+}$ion. The higher concentration in the linear response range and faster response time demonstrated by the
AuNPs-modified biosensor may be useful for the analysis of waste water sample, for example, sewage without further dilution where the $\mathrm{NH}_{4}{ }^{+}$ion concentration is normally high.

\section{Acknowledgments}

The authors would like to acknowledge Universiti Kebangsaan Malaysia (UKM) for an operational research fund (UKM-OUP-NBT-29-151-2011) and the UKM Chancellor Foundation Sponsorship awarded to Tan Ling Ling through the UKM-Global Student Mobility Partnership Programme.

\section{References}

[1] S. E. Bennett, Fabrication of water-soluble gold nanoparticle aggregate, Bsc dissertation, Massachusetts Institute of Technology, 2006.

[2] F. K. Liu, Y. T. Hsu, and C. H. Wu, "Open tubular capillary electrochromatography using capillaries coated with films of alkanethiol-self-assembled gold nanoparticle layers," Journal of Chromatography A, vol. 1083, no. 1-2, pp. 205-214, 2005.

[3] A. K. A. Aliganga, A. S. Duwez, and S. Mittler, "Binary mixtures of self-assembled monolayers of 1,8-octanedithiol and 1-octanethiol for a controlled growth of gold nanoparticles," Organic Electronics, vol. 7, no. 5, pp. 337-350, 2006.

[4] P. Pang, J. Guo, S. Wu, and Q. Cai, "Humidity effect on the dithiol-linked gold nanoparticles interfaced chemiresistor sensor for VOCs analysis," Sensors and Actuators B, vol. 114, no. 2, pp. 799-803, 2006.

[5] A. Sivanesan, P. Kannan, and S. A. John, "Electrocatalytic oxidation of ascorbic acid using a single layer of gold nanoparticles immobilized on 1,6-hexanedithiol modified gold electrode," Electrochimica Acta, vol. 52, no. 28, pp. 8118-8124, 2007.

[6] N. M. Voros, R. Patakfalvi, and I. Dekany, "Alkylthiolfunctionalized AuNPs for sensing organic vapours: theconnection between the adsorption isotherm and the sensor resistance," Colloids and Surfaces A, vol. 329, pp. 205-210, 2008.

[7] M. S. El- Deab and T. Ohsaka, "An extraordinary electrocatalytic reduction of oxygen on gold nanoparticles-electrodeposited gold electrodes," Electrochemistry Communications, vol. 4, no. 4, pp. 288-292, 2002.

[8] M. S. El-Deab and T. Ohsaka, "Hydrodynamic voltammetric studies of the oxygen reduction at gold nanoparticles-electrodeposited gold electrodes," Electrochimica Acta, vol. 47, no. 26, pp. 4255-4261, 2002.

[9] S. K. Dondapati, P. L. Sanchez, and I. Katakis, "Controlled electrophoretic deposition of multifunctional nanomodules for bioelectrochemical applications," Biosensors and Bioelectronics, vol. 24, no. 1, pp. 55-59, 2008. 
[10] M. L. Mena, P. Y. Sedeno, and J. M. Pingarron, "A comparison of different strategies for the constructionof amperometric enzyme biosensors using goldnanoparticle-modified electrodes," Analytical Biochemistry, vol. 336, pp. 20-27, 2005.

[11] N. Fishelson, I. Shkrob, O. Lev, J. Gun, and A. D. Modestov, "Studies on charge transport in self-assembled gold-dithiol films: conductivity, photoconductivity, and photoelectrochemical measurements," Langmuir, vol. 17, no. 2, pp. 403412, 2001.

[12] S. Zhang, N. Wang, H. Yu, Y. Niu, and C. Sun, "Covalent attachment of glucose oxidase to an Au electrode modified with gold nanoparticles for use as glucose biosensor," Bioelectrochemistry, vol. 67, no. 1, pp. 15-22, 2005.

[13] K. C. Grabar, R. G. Freeman, M. B. Hommer, and M. J. Natan, "Preparation and characterization of Au colloid monolayers," Analytical Chemistry, vol. 67, no. 4, pp. 735-743, 1995.

[14] J. M. Pingarron, P. Y. Sedeno, and A. G. Cortes, "Gold nanoparticle-based electrochemical biosensors," Electrochimica Acta, vol. 53, pp. 5848-5866, 2008.

[15] A. Escorcia and A. A. Dhirani, "Electrochemical properties of ferrocenylalkane dithiol-gold nanoparticle films prepared by layer-by-layer self-assembly," Journal of Electroanalytical Chemistry, vol. 601, no. 1-2, pp. 260-268, 2007.

[16] N. J. Renault, A. Senillou, C. Martelet, K. Wan, and J. M. Chovelon, "ISFET microsensors for the detection of pollutants in liquid media," Sensors and Actuators B, vol. 59, no. 2, pp. 154-164, 1999.

[17] M. Trinkel, W. Trettnak, F. Reininger, R. Benes, P. O’Leary, and O. S. Wolfbeis, "Study of the performance of an optochemical sensor for ammonia," Analytica Chimica Acta, vol. 320, no. 23, pp. 235-243, 1996.

[18] K. Waich, T. Mayr, and I. Klimant, "Fluorescence sensors for trace monitoring of dissolved ammonia," Talanta, vol. 77, no. 1, pp. 66-72, 2008.

[19] T. Ohashima and K. Soda, "Purification and properties of alanine dehydrogenase from Bacillus sphaericus," European Journal of Biochemistry, vol. 100, no. 1, pp. 29-39, 1979.

[20] J. Tkac and J. J. Davis, "An optimised electrode pre-treatment for SAM formation on polycrystalline gold," Journal of Electroanalytical Chemistry, vol. 621, no. 1, pp. 117-120, 2008.

[21] S. M. Low, Y. H. Lee, M. Y. Bohari, and A. Musa, "A novel salicylic acid optical fibre probe fabrication," Thin Solid Films, vol. 477, pp. 104-110, 2005.

[22] L. A. Lyon, M. D. Musick, P. C. Smith, B. D. Reiss, D. J. Peña, and M. J. Natan, "Surface plasmon resonance of colloidal Aumodified gold films," Sensors and Actuators B, vol. 54, no. 1, pp. 118-124, 1999.

[23] D. Ågren, M. Stehr, C. L. Berthold et al., "Three-dimensional structures of Apo- and Holo-l-alanine dehydrogenase from mycobacterium tuberculosis Reveal conformational changes upon coenzyme binding," Journal of Molecular Biology, vol. 377, no. 4, pp. 1161-1173, 2008.

[24] S. I. Hashimoto and R. Katsumata, "L-alanine fermentation by an alanine racemase-deficient mutant of the DL-alanine hyperproducing bacterium Arthrobacter oxydans HAP-1," Journal of Fermentation and Bioengineering, vol. 86, no. 4, pp. 385-390, 1998.

[25] S. I. Kato, T. Ohshima, A. Galkin, L. Kulakova, T. Yoshimura, and N. Esaki, "Purification and characterization of alanine dehydrogenase from a marine bacterium, Vibrio proteolyticus," Journal of Molecular Catalysis B, vol. 23, no. 2-6, pp. 373 378, 2003.

[26] H. M. Nassef, A. E. Radi, and C. K. O'Sullivan, "Electrocatalytic sensing of NADH on a glassy carbon electrode modified with electrografted o-aminophenol film," Electrochemistry Communications, vol. 8, no. 11, pp. 1719-1725, 2006.

[27] A. Chovin, P. Garrigue, and N. Sojic, "Remote NADH imaging through an ordered array of electrochemiluminescent nanoapertures," Bioelectrochemistry, vol. 69, no. 1, pp. 25-33, 2006.

[28] L. K. Shyuan, L. Y. Heng, M. Ahmad, S. A. Aziz, and Z. Ishak, "Screen-printed biosensor with alkaline phosphatase immobilized in sol-gel/chitosan film for the detection of 2,4dichlorophenoxyacetic acid," Sensor Letters, vol. 4, no. 1, pp. 17-21, 2006

[29] C. R. Raj and S. Behera, "Mediatorless voltammetric oxidation of NADH and sensing of ethanol," Biosensors and Bioelectronics, vol. 21, no. 6, pp. 949-956, 2005.

[30] S. Behera and C. R. Raj, "Self-assembled monolayers of thiosubstituted nucleobases on gold electrode for the electroanalysis of NADH, ethanol and uric acid," Sensors and Actuators B, vol. 128, no. 1, pp. 31-38, 2007.

[31] G. Bayramoǧlu, S. Akgöl, A. Bulut, A. Denizli, and M. Y. Arica, "Covalent immobilisation of invertase onto a reactive film composed of 2-hydroxyethyl methacrylate and glycidyl methacrylate: properties and application in a continuous flow system," Biochemical Engineering Journal, vol. 14, no. 2, pp. 117-126, 2003.

[32] I. Schröder, A. Vadas, E. Johnson, S. Lim, and H. G. Monbouquette, "A novel archaeal alanine dehydrogenase homologous to ornithine cyclodeaminase and $\mu$-crystallin," Journal of Bacteriology, vol. 186, no. 22, pp. 7680-7689, 2004.

[33] P. W. Carr and L. D. Bowers, Immobilised Enzymes in Analytical and Clinical Chemistry, John Wiley \& Sons, New York, NY, USA, 1980.

[34] A. H. Sharina, Y. H. Lee, and A. Musa, "Effects of gold nanoparticles on the response of phenol biosensor containing photocurable membrane with tyrosinase," Sensors, vol. 8, no. 10, pp. 6407-6416, 2008.

[35] O. Shulga and J. R. Kirchhoff, "An acetylcholinesterase enzyme electrode stabilized by an electrodeposited gold nanoparticle layer," Electrochemistry Communications, vol. 9, no. 5, pp. 935940, 2007.

[36] P. Bertocchi, D. Compagnone, and G. Palleschi, "Amperometric ammonium ion and urea determination with enzymebased probes," Biosensors and Bioelectronics, vol. 11, no. 1-2, pp. 1-10, 1996.

[37] R. C. H. Kwan, P. Y. T. Hon, and R. Renneberg, "Amperometric determination of ammonium with bienzyme/poly (carbamoyl) sulfonate hydrogel-based biosensor," Sensors and Actuators B, vol. 107, no. 2, pp. 616-622, 2005. 

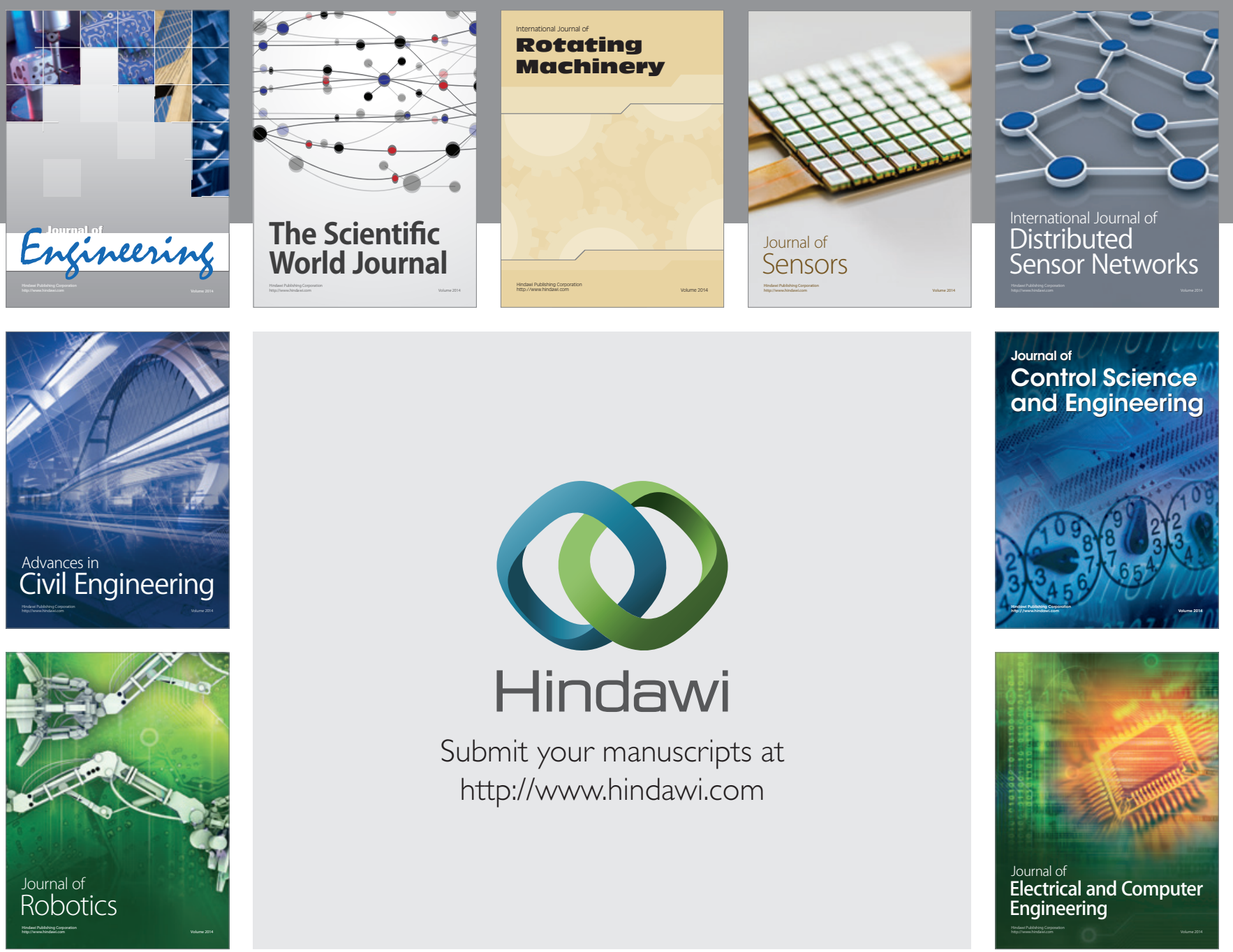

Submit your manuscripts at

http://www.hindawi.com
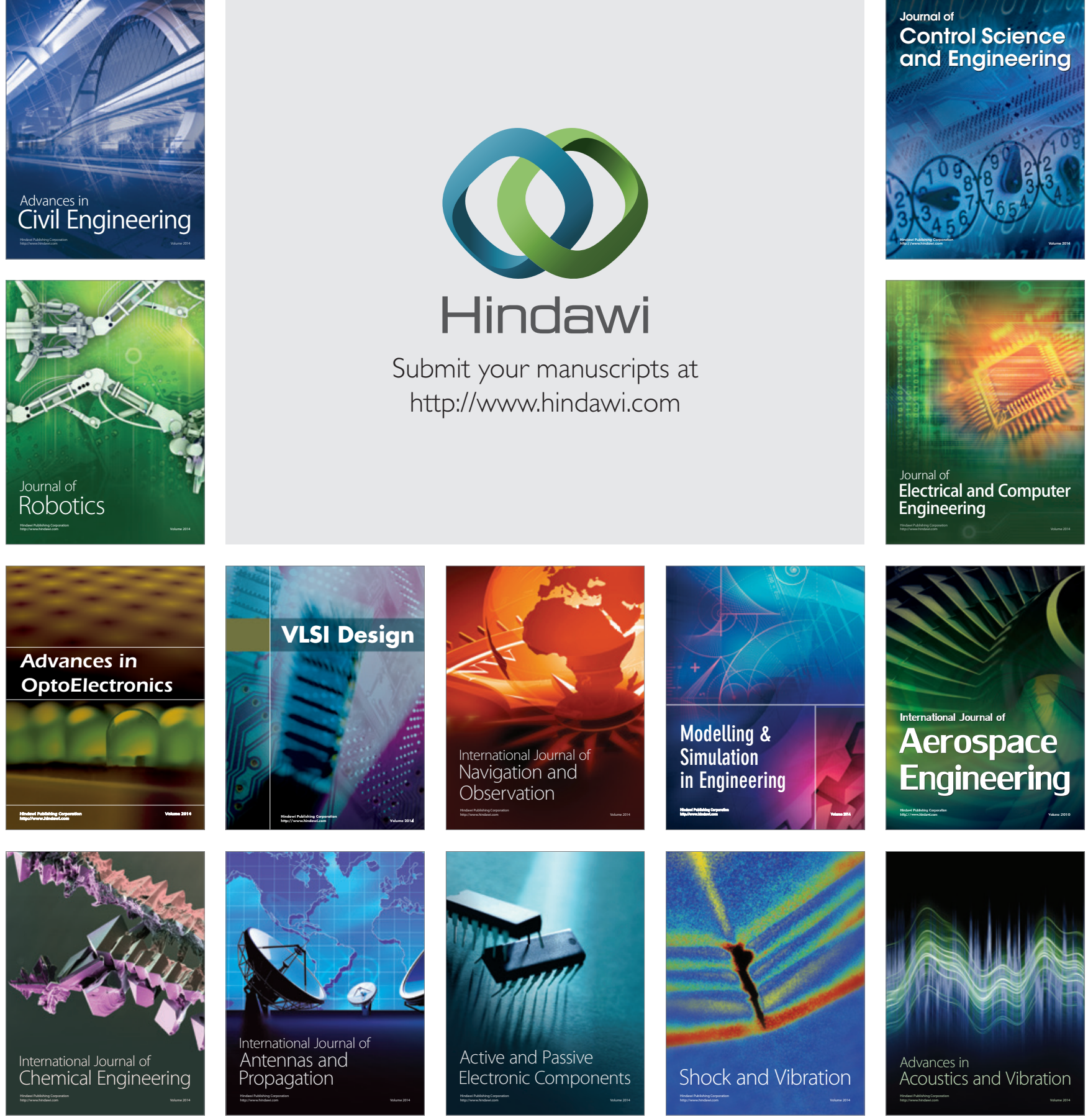